\title{
Fast recovery of cardiac function in PIMS-TS patients early using intravenous anti-IL-1 treatment
}

\author{
Maria Vincenza Mastrolia ${ }^{1 *}$ (D), Edoardo Marrani ${ }^{1}$, Giovanni Battista Calabri², Manuela L'Erario ${ }^{3}$, Ilaria Maccora', \\ Silvia Favilli ${ }^{2}$, Pier Paolo Duchini ${ }^{3}$, Ilaria Pagnini ${ }^{1}$ and Gabriele Simonini ${ }^{4}$
}

Keywords: PMIS-TS, Kawasaki disease, COVID 19, SARS CoV-2 infection

\section{To the editor,}

We read with interest the manuscript entitled "Anakinra treatment in critically ill COVID-19 patients: a prospective cohort study" by Kooistra et al. [1] reporting the potential efficacy of anakinra (ANA) to control the hyperinflammation in COVID-19 patients.

In our clinical practice, we adopted the early use of intravenous ANA for the treatment of cardiac disfunction in Pediatric Inflammatory Multisystem Syndrome temporally associated with SARS CoV-2 infection (PIMS-TS) patients. During the second COVID-19 wave, 9 PIMS-TS children were admitted to Meyer Children's University Hospital in Florence (mean age of 10.2 y [IQR] 8.5-13). Echocardiography revealed a left ventricular ejection fraction (LVEF) $\leq 40 \%$ in $5 / 9$ patients. In these 5 children, ANA was adopted as first-line therapy and administered as continuous intravenous infusion at $10 \mathrm{mg} / \mathrm{kg} /$ day (400 $\mathrm{mg} /$ day maximum dose). Within the first day of ANA therapy, fractionated IVIG $(2 \mathrm{~g} / \mathrm{kg})$ and intravenous steroids (one methylprednisolone pulses $[30 \mathrm{mg} / \mathrm{kg} /$ day, maximum $1 \mathrm{~g} /$ day] in 3 consecutive days followed by $1 \mathrm{mg} / \mathrm{kg} /$ day intravenous methylprednisolone) were subsequently associated. At median time of $24 \mathrm{~h}$ (range

This comment refers to the article available online at https://doi.org/10.1186/ s13054-020-03364-w.

*Correspondence: maria.mastrolia@unifi.it

${ }^{1}$ Rheumatology Unit, Meyer Children's University Hospital, Viale Gaetano Pieraccini, 24, 50139 Firenze, Italy

Full list of author information is available at the end of the article
12-36 h) from starting ANA, all patients restored LVEF to $>55 \%$ along with a progressive reduction of troponin and N-terminal pro B-type natriuretic peptide (NT proBNP) values (Fig. 1). A concomitant reduction until discontinuation of inotropic support was obtained together with the recovery of clinical sings and inflammatory parameters.

In order to prevent the inflammatory rebound, ANA therapy was tapered in 2 weeks, then switched subcutaneously and stopped after 5 weeks (range 4-6).

One month after discharge, echocardiography reported stably normal findings.

The early use of ANA prompted a rapid and sub-stained LEVF improvement over one day from admission. Our results further support the assumption that an aggressive, early and overtime immunomodulatory approach in PIMS-TS patients with myocardial involvement may induce a faster time to recovery, as quickly damping the cytokine storm [2,3]. However, the cumulative effect of ANA in combination with subsequent IVIG and steroid use could be advocated as effective in restoring a normal LVEF. Due to the poor peripheral perfusion and hemodynamic instability into the early phases of PIMS-TS, continuous intravenous infusion may be the preferable administration route. Subcutaneous injections might be considered as maintenance therapy after achieving stable conditions [3].

Future randomized controlled trials and long-term follow-up could test the hypothesis that a step-down original author(s) and the source, provide a link to the Creative Commons licence, and indicate if changes were made. The images or other third party material in this article are included in the article's Creative Commons licence, unless indicated otherwise in a credit line to the material. If material is not included in the article's Creative Commons licence and your intended use is not permitted by statutory regulation or exceeds the permitted use, you will need to obtain permission directly from the copyright holder. To view a copy of this licence, visit http://creativecommons.org/licenses/by/4.0/. The Creative Commons Public Domain Dedication waiver (http://creativeco mmons.org/publicdomain/zero/1.0/) applies to the data made available in this article, unless otherwise stated in a credit line to the data. 


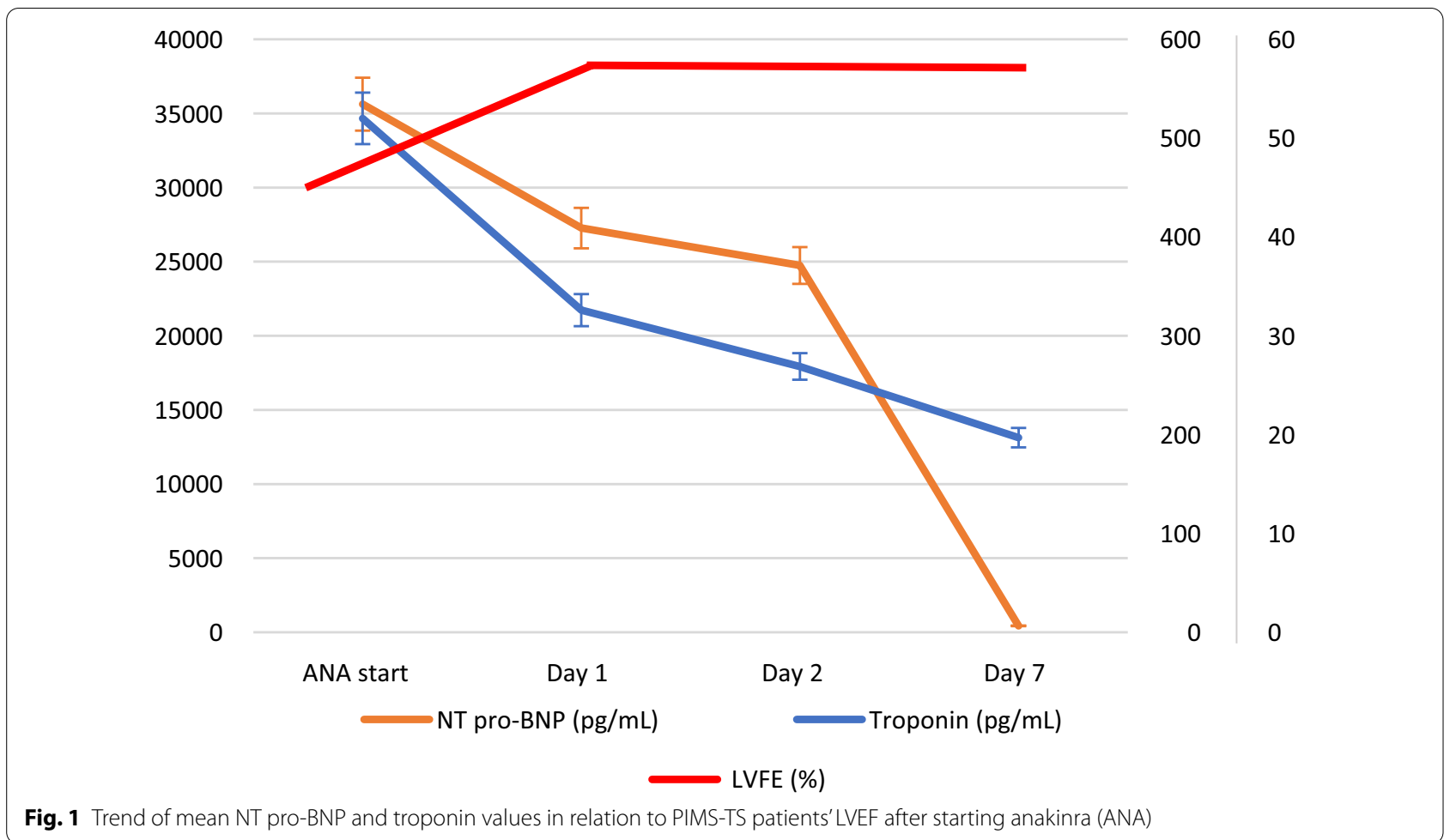

immunomodulatory approach could be preferred in PIMS-TS patients experiencing myocardial disfunction to avoid a further progression and/or the onset of sequalae over time.

\section{Author's reply \\ Emma J. Kooistra ${ }^{5,6}$, Matthijs Kox ${ }^{5,6}$ and Peter Pickkers ${ }^{5,6^{*}}$ \\ *Correspondence: peter.pickkers@radboudumc.nl \\ ${ }^{5}$ Department of Intensive Care Medicine, Radboud University Medical \\ Center, 6500 HB Nijmegen, The Netherlands \\ ${ }^{6}$ Radboud Center for Infectious Diseases, Radboud University Medical \\ Center, 6500 HB Nijmegen, The Netherlands}

\section{Anakinra to treat COVID-19-related hyperinflammation}

We thank Mastrolia and colleagues for their letter in response to our study. They describe the use of anakinra in 5 pediatric patients suffering from Pediatric Inflammatory Multisystem Syndrome temporally associated with Severe Acute Respiratory Syndrome Coronavirus 2
(SARS-CoV-2) infection (PIMS-TS) and a left ventricular ejection fraction (LVEF) $\leq 40 \%$. Within $36 \mathrm{~h}$, both LVEF and cardiac biomarkers recovered, enabling discontinuation of inotropic support in all patients.

Although severe pediatric cases of SARS-CoV-2 infection are rare, children with PIMS-TS present with a complex multisystem inflammatory syndrome which often necessitates admission to the Intensive Care Unit (ICU). This syndrome is distinct from Coronavirus Disease 2019 (COVID-19), not only in terms of clinical features, but also because PIMS-TS may manifest up to weeks after SARS-CoV-2 infection [4]. Cardiac function, as in the 5 cases reported by Mastrolia et al., is commonly affected in patients presenting with PIMS-TS [5]. Furthermore, preclinical data have shown beneficial effects of anakinra in Kawasaki disease [6], which shares many features with PIMS-TS, which may have prompted Mastrolia et al. to initiate this therapy.

\section{(See figure on next page.)}

Fig. 2 Plasma levels of a C-reactive protein, b procalcitonin, c white blood cell counts, $\mathbf{d}$ ferritin, and $\mathbf{e}$ body temperature on day of admission to the intensive care unit (ICU), start of anakinra therapy, and until 8 days following cessation of anakinra. Results of 13 anakinra-treated patients of which data were available on multiple days after cessation of anakinra treatment are shown. Data are presented as geometric mean with $95 \%$ confidence intervals. Anakinra therapy was initiated 12 [7-17] and ceased 22 [18-25] days following ICU admission (median [IQR]). P-values were calculated using paired t-tests and mixed effect model analysis on log-transformed data. No inflammatory rebound effect was observed following cessation of anakinra therapy 
Mastrolia et al. Crit Care $\quad$ (2021) 25:131

Page 3 of 4

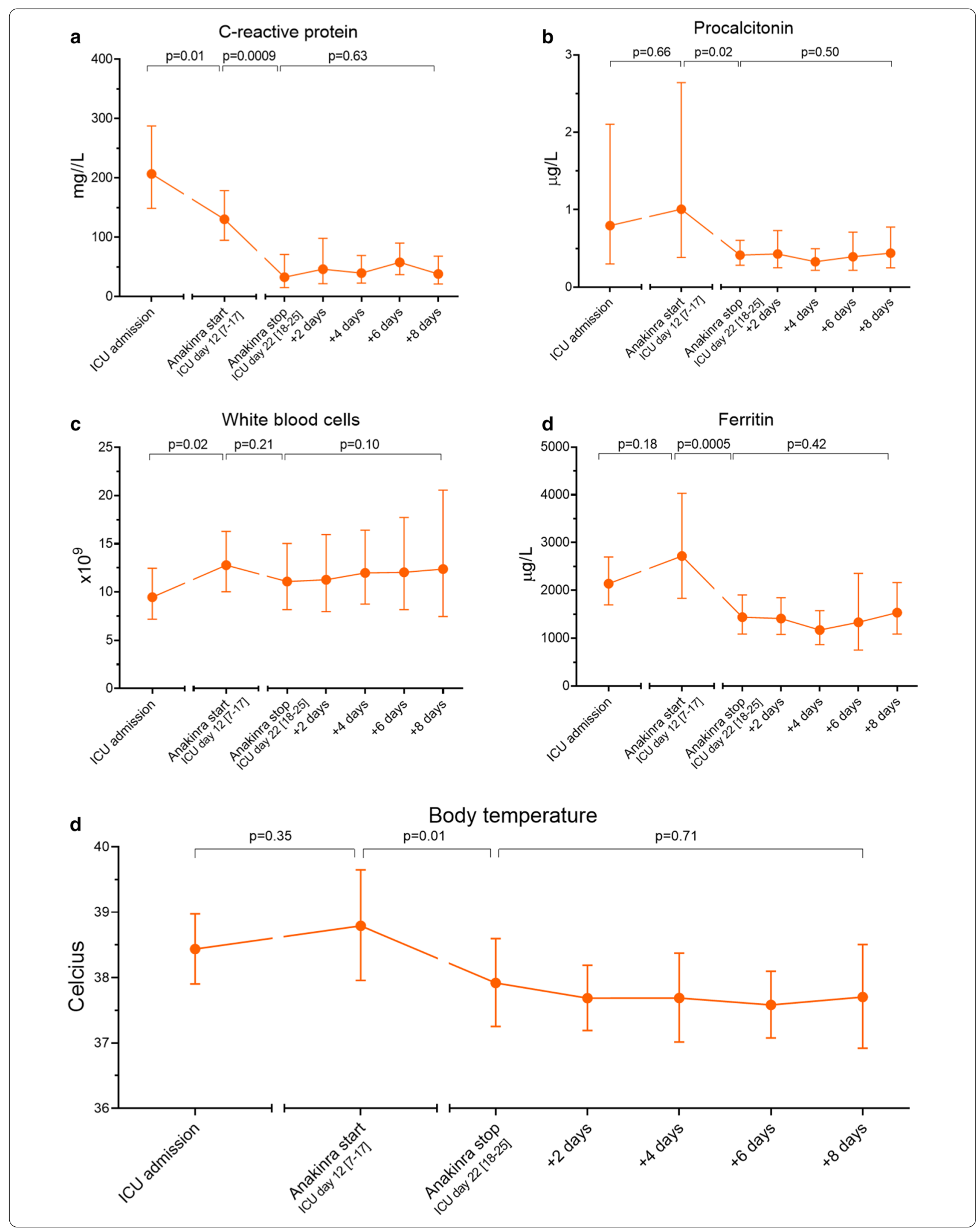


While the results presented by Mastrolia and colleagues are encouraging, several aspects clearly limit the conclusions. First, no control group receiving standard care was included. This is of relevance, as previous reports describe that LVEF may also recover fairly quickly without anakinra treatment [5]. Second, the authors used anakinra in combination with high-dose methylprednisolone and intravenous immunoglobulins. Especially the use of high dosages of corticosteroids impedes proper assessment of the effects of anakinra. Third, anakinra treatment was tapered over a period of 5 weeks, to prevent an inflammatory rebound according to the authors. In our study in critically ill COVID-19 patients [1], anakinra treatment was not tapered. Inspired by the strategy of Mastrolia et al., we assessed whether cessation of anakinra treatment resulted in an increase in inflammatory parameters in our COVID-19 patients. We analyzed our data until 8 days after cessation of anakinra, which, given the half-life of 4-6 h, should reveal a rebound effect, if present. As depicted in Fig. 2 however, no such inflammatory rebound effect was observed.

Taken together, the interesting findings by Mastrolia and colleagues certainly warrant further study in a more controlled setting. Our results indicate that, in adult COVID-19 patients, a rebound inflammatory response does not occur when anakinra is stopped, indicating that tapering of anakinra treatment is not necessary in this patient category.

\section{Acknowledgements}

Not applicable.

\section{Authors' contributions}

MVM collected the data. GS and MVM designed the study. MVM wrote the first draft of the manuscript. All the authors revised and accepted the manuscript.

\section{Funding}

No funding was secured for this study.

\section{Availability of data and materials}

The complete clinical reports of each patient are available for the reviewers if requested.

\section{Declarations}

Ethics approval and consent to participate Not applicable.
Consent for publication

All authors agreed for pblication.

\section{Competing interests}

The authors have no example conflicts of interest to disclose..

\section{Author details}

${ }^{1}$ Rheumatology Unit, Meyer Children's University Hospital, Viale Gaetano Pieraccini, 24, 50139 Firenze, Italy. ${ }^{2}$ Cardiologic Unit, Meyer Children's University Hospital, Firenze, Italy. ${ }^{3}$ Pediatric Intensive Care Unit, Meyer Children's University Hospital, Firenze, Italy. ${ }^{4}$ Rheumatology Unit, NEUROFARBA Department, Meyer Children's University Hospital, University of Florence, Firenze, Italy.

Received: 10 March 2021 Accepted: 23 March 2021

Published online: 07 April 2021

\section{References}

1. Kooistra EJ, Waalders NJB, Grondman I, Janssen NAF, de Nooijer AH, Netea MG, et al. Anakinra treatment in critically ill COVID-19 patients: a prospective cohort study. Crit Care. 2020;24(1):688.

2. Belhadjer Z, Méot M, Bajolle F, Khraiche D, Legendre A, Abakka S, et al. Acute heart failure in multisystem inflammatory syndrome in children in the context of global SARS-CoV-2 pandemic. Circulation. 2020;142(5):429-36.

3. Belhadjer Z, Auriau J, Méot M, Oualha M, Renolleau S, Houyel L, et al. Addition of corticosteroids to immunoglobulins is associated with recovery of cardiac function in multi-inflammatory syndrome in children. Circulation. 2020;142(23):2282-4.

4. Evans C, Davies P. SARS-CoV-2 paediatric inflammatory syndrome. Paediatr Child Health. 2021;31(3):110-5.

5. Ramcharan T, Nolan O, Lai CY, Prabhu N, Krishnamurthy R, Richter AG, et al. Paediatric inflammatory multisystem syndrome: temporally associated with SARS-CoV-2 (PIMS-TS): cardiac features, management and short-term outcomes at a UKTertiary Paediatric Hospital. Pediatr Cardiol. 2020;41(7):1391-401.

6. Gorelik M, Lee Y, Abe M, Andrews T, Davis L, Patterson J, et al. IL-1 receptor antagonist, anakinra, prevents myocardial dysfunction in a mouse model of Kawasaki disease vasculitis and myocarditis. Clin Exp Immunol. 2019;198(1):101-10.

\section{Publisher's Note}

Springer Nature remains neutral with regard to jurisdictional claims in published maps and institutional affiliations.

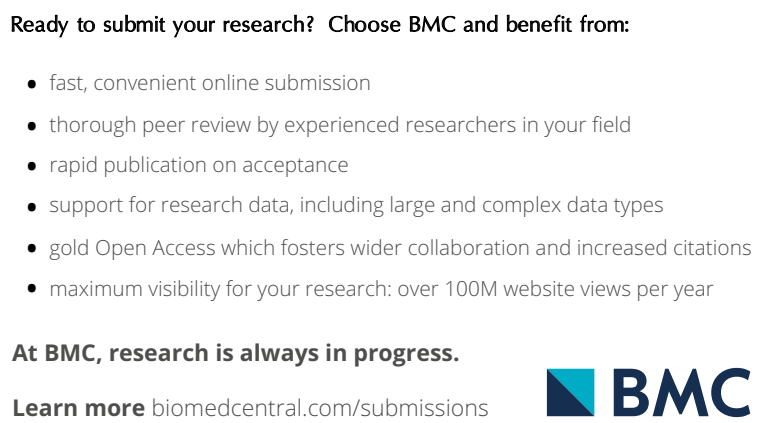

